\title{
Vertical Profiles of Ethane and Propane in the Stratosphere
}

\author{
J. Rudolph, D. H. EhHALt, AND A. TÓNNISSEN
}

Institut für Chemie, Atmosphärische Chemie, Kernforschungsanlage Jilich GmbH, D-5170 Julich, Federal Republic of Germany

Stratospheric measurements of the $\mathrm{C}_{2} \mathrm{H}_{6}$ mixing ratio up to $30 \mathrm{~km}$ and of the $\mathrm{C}_{3} \mathrm{H}_{8}$ mixing ratio up to $18 \mathrm{~km}$ altitude are reported. The observed vertical gradient of $\mathrm{C}_{2} \mathrm{H}_{6}$ is much weaker than that calculated from a one-dimensional steady state model, indicating lower concentrations of atomic chlorine in the lower stratosphere than those predicted by models. From the measured $\mathrm{C}_{2} \mathrm{H}_{6}$ profile a tentative estimate for the $\mathrm{Cl}$ concentration is derived.

\section{INTRODUCTION}

Balloon-borne cryogenic collection provides relatively large samples (10 1 STP) of uncontaminated stratospheric air. This facilitates the simultaneous measurement of a large number of trace gases to high stratospheric altitudes. We have now extended our program to include the measurement of light nonmethane hydrocarbons, $C_{2}$ to $C_{3}$, and we report here our first measurements of ethane, $\mathrm{C}_{2} \mathrm{H}_{6}$, and propane, $\mathrm{C}_{3} \mathrm{H}_{8}$, in the stratosphere.

The tropospheric background mixing ratios of both are quite low, about $2 \mathrm{ppb}$ for $\mathrm{C}_{2} \mathrm{H}_{6}$ and less than $1 \mathrm{ppb}$ for $\mathrm{C}_{3} \mathrm{H}_{8}$ [Rudolph et al., 1979]. The fluxes of these gases into the stratosphere are small, and their impact on the stratospheric carbon and hydrogen budget is negligible. Nevertheless, $\mathrm{C}_{2} \mathrm{H}_{6}$ reacts rapidly with $\mathrm{Cl}$ atoms, and its presence should significantly decrease the $\mathrm{Cl}$ atom concentration in the lower stratosphere [Aikin et al., 1979]. Furthermore, already the first model calculations [Chameides and Cicerone, 1978] indicated that the reaction with $\mathrm{Cl}$ atoms is by far the dominant loss mechanism of $\mathrm{C}_{2} \mathrm{H}_{6}$ in the stratosphere. Hence its vertical distribution should be controlled by the vertical distribution of the $\mathrm{Cl}$ concentration. Consequently, measured profiles of $\mathrm{C}_{2} \mathrm{H}_{6}$ could serve as a convenient method for determination of the vertical profile of $\mathrm{Cl}$ atoms in the lower stratosphere, a region where direct observations of $\mathrm{Cl}$ are not yet feasible. Here we use our present $\mathrm{C}_{2} \mathrm{H}_{6}$ profiles to derive an estimate for the $\mathrm{Cl}$ concentration in the lower stratosphere.

\section{Expermmental Procedures}

The stratospheric air samples were collected by a balloonborne cryosampler similar to the design developed by Lueb et al. [1975]. The sampling procedures have been presented elsewhere [Fabian et al., 1979a]. The tropospheric air samples were collected aboard an aircraft by grab sampling in electropolished stainless steel containers of 2-1 volume. After return to the laboratory the air samples of 1-5 1 STP were analyzed for their hydrocarbon content using a specially equipped gas chromatograph: The hydrocarbons are first enriched on a precolumn packed with Spherosil and Carbosieve $B$ and cooled to temperatures of about $150 \mathrm{~K}$, then thermally desorbed and separated on a column packed with Spherosil XOB 075 (6 m long and $0.8 \mathrm{~mm}$ inner diameter), and finally detected with a flame ionization detector. The gas chromatographic measurements were calibrated with standard mixtures of 0.5-3 ppb of $\mathrm{C}_{2} \mathrm{H}_{6}$ and $\mathrm{C}_{3} \mathrm{H}_{8}$ in synthetic air, which were prepared by three-step dilution in a static dilution system. The detection limits depended on actual sample size and were 2

Copyright (c) 1981 by the American Geophysical Union.

Copyright 91981

0148-0227/81/001C-0462\$01.00 ppt for $\mathrm{C}_{2} \mathrm{H}_{6}$ at $30 \mathrm{~km}$ altitude and 10 ppt for $\mathrm{C}_{3} \mathrm{H}_{8}$ at $18 \mathrm{~km}$ altitude. The errors of the gas chromatographic measurement are $10 \%$ for tropospheric mixing ratios; they, increase to a factor 2 for samples with mixing ratios near the detection limit.

\section{RESULTS}

The stratospheric data were obtained from two balloon flights over southern France at $44^{\circ} \mathrm{N}$ on June 16 and 28, 1979. The tropospheric samples were collected during an aircraft flight on June 16, 1979. The sampling was part of a joint project for the measurement of stratospheric trace gases by the Kernforschungsanlage Jülich, the Max-Planck-Institut für Aeronomie in Lindau, and the Max-Planck-Institut für Chemie in Mainz. In addition to $\mathrm{C}_{2} \mathrm{H}_{6}$ and $\mathrm{C}_{3} \mathrm{H}_{B}$ the tropospheric samples also showed measurable concentrations of $\mathrm{C}_{2} \mathrm{H}_{4}, \mathrm{C}_{2} \mathrm{H}_{2}, n-\mathrm{C}_{4} \mathrm{H}_{10}, i-\mathrm{C}_{4} \mathrm{H}_{10}, n-\mathrm{C}_{5} \mathrm{H}_{12}$, and $i-\mathrm{C}_{5} \mathrm{H}_{12}$. Only $\mathrm{C}_{2} \mathrm{H}_{2}, \mathrm{C}_{2} \mathrm{H}_{6}$, and $\mathrm{C}_{3} \mathrm{H}_{8}$ could be detected in stratospheric air samples above $15 \mathrm{~km}$ altitude.

The $\mathrm{C}_{3} \mathrm{H}_{8}$ and $\mathrm{C}_{2} \mathrm{H}_{6}$ data are summarized in Figures 1 and 2. The measured $\mathrm{C}_{3} \mathrm{H}_{8}$ mixing ratio decreases extremely fast with altitude above the tropopause $(11 \mathrm{~km})$. Above $18 \mathrm{~km}$ altitude it is already below the detection limit of $10 \mathrm{ppt}$.

The measured stratospheric $\mathrm{C}_{2} \mathrm{H}_{6}$ mixing ratios (Figure 2) exhibit a similar rapid decrease with altitude. Because of its higher tropospheric mixing ratio, $2 \mathrm{ppb}$, and a lower detection limit, 2 ppt, the $\mathrm{C}_{2} \mathrm{H}_{6}$ can be observed to about $30 \mathrm{~km}$ altitude. Between the tropopause and $30 \mathrm{~km}$ the $\mathrm{C}_{2} \mathrm{H}_{6}$ mixing ratio drops more or less steadily by 3 orders of magnitude. However, the uppermost samples, although collected during descent, show elevated $\mathrm{C}_{2} \mathrm{H}_{6}$ mixing ratios for both flights. This is a clear indication of $\mathrm{C}_{2} \mathrm{H}_{6}$ contamination. Since the other trace gases measured for these flights do not show such a reversal in the vertical gradient, the elevated $\mathrm{C}_{2} \mathrm{H}_{6}$ concentration cannot be ascribed to stratospheric transport.

There are various steps in the sample collection and handling procedures at which contamination can occur: (1) leakage in the vacuum lines used for sample transfer, (2) leakage through the valves of the sample containers during storage, (3) outgassing of the various sample containers, (4) outgassing from the inner walls of the cryogenic sampler during collection (e.g., inlet line), and (5) outgassing from the external surfaces of balloon and payload during sample collection. Points 1 and 2 can be excluded with some certainty: Leakage would admix tropospheric air to the stratospheric samples and would cause contamination in all trace gases with high troposphericstratospheric concentration differences. This has not been observed. Point $3, \mathrm{C}_{2} \mathrm{H}_{6}$ outgassing of the sample containers, seems to be negligible, as shown by blank experiments. This 


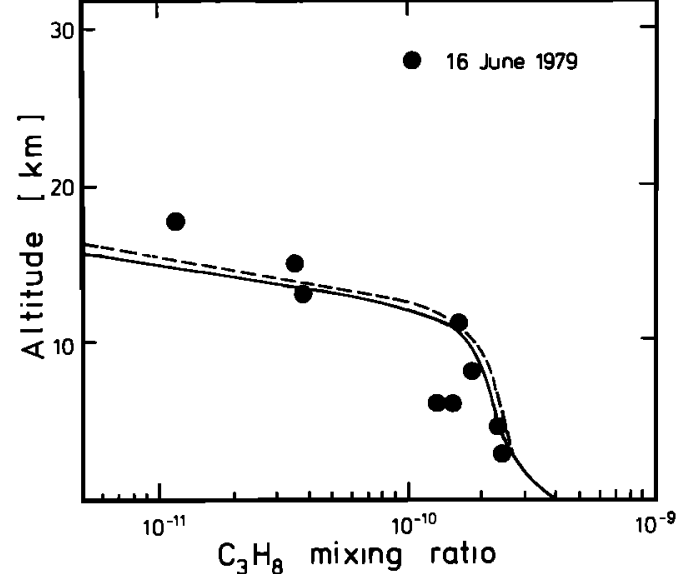

Fig. 1. Vertical profile of the $\mathrm{C}_{3} \mathrm{H}_{8}$ mixing ratio measured in the lower stratosphere over southem France, $44^{\circ} \mathrm{N}$ latitude. Solid and dashed curves represent model-predicted $\mathrm{C}_{3} \mathrm{H}_{8}$ profiles.

leaves internal or external outgassing of $\mathrm{C}_{2} \mathrm{H}_{6}$ in flight as most likely sources of contamination.

Indeed, samples from a balloon flight in November 1979 over southern France, which had to be collected during ascent rather than descent because of limited flight time, showed substantially higher mixing ratios of $\mathrm{C}_{2} \mathrm{H}_{6}$ and $\mathrm{C}_{3} \mathrm{H}_{8}$ than those presented here, especially above $20 \mathrm{~km}$ altitude. This strongly indicates in-flight contamination. These data also indicate that the $\mathrm{C}_{2} \mathrm{H}_{6}$ outgassing rate drops rapidly with time, about an order of magnitude per hour.

Having narrowed the likely sources to in-flight contamination, we can try to estimate its extent. The sample collection rate of the cryosampler is inversely proportional to the square of the air pressure $p$ [Lueb et al., 1975, Figure 3]. Thus in the case of internal contamination the ratio of contamination rate to sampling rate will decrease with decreasing sampling altitude at least as $1 / p^{2}$ even if we admit a constant outgassing rate. In the case of external outgassing the released contamination will be diluted with surrounding air of pressure

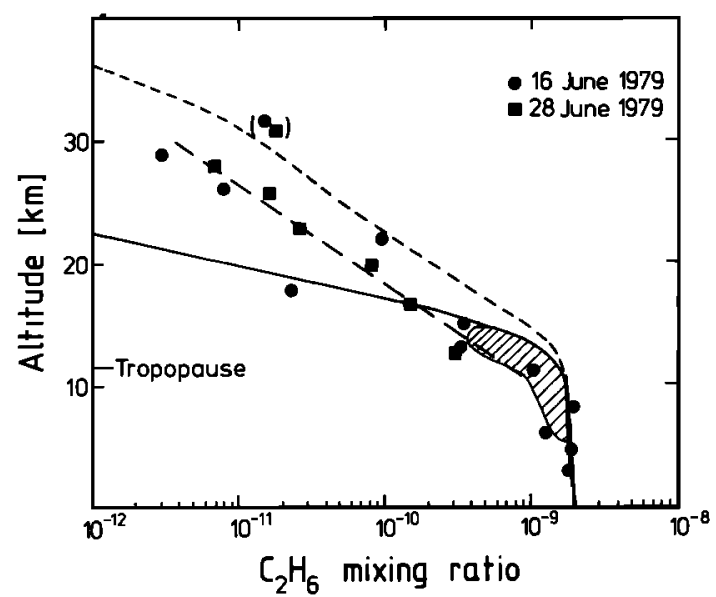

Fig. 2. Vertical profiles of the $\mathbf{C}_{2} \mathrm{H}_{6}$ mixing ratio in the stratosphere over southern France, $44^{\circ} \mathrm{N}$ latitude. The dash-dotted line represents a least squares fit of an exponential profile to the data excluding the data in parentheses, which are obviously contaminated. The hatched area shows the range of data by Cronn and Robinson [1979a]. The solid curve represents the $\mathrm{C}_{2} \mathrm{H}_{6}$ profile predicted by a one-dimensional steady state model. The dashed curve is a prediction neglecting reaction of $\mathrm{C}_{2} \mathrm{H}_{6}$ with $\mathrm{Cl}$. $p$, and the contamination will decrease with decreasing altitude at least as $1 / p$. An estimate of contamination decreasing as $1 / p$ with altitude based on the assumption of external outgassing with constant rate will therefore be rather conservative.

Applying this estimate to the actual flights and assuming that the $\mathrm{C}_{2} \mathrm{H}_{6}$ measured in the samples at the second highest altitudes (28.9 and $27.9 \mathrm{~km}$, respectively) were completely caused by contamination, the next lowest samples $(26 \mathrm{~km})$ would have a contribution by contamination of less than $30 \%$, and the lower samples of less than $10 \%$. The latter value is less than the precision of the gas chromatographic measurement. This rapid falloff in contamination with decreasing altitude is also indicated by the rapid drop of a factor of 2-4 in mixing ratio between the highest and next highest samples observed during the flights in June 1979 (Figure 2). Although there remains an element of uncertainty until the actual source of contamination is identified and removed, it appears safe to assume that the $\mathrm{C}_{2} \mathrm{H}_{6}$ mixing ratios at and below $26 \mathrm{~km}$ are little affected by contamination.

The stratospheric data points shown in Figure 2 fall essentially on a straight line. Since contamination below $30 \mathrm{~km}$ altitude is small, the measured decrease in $\mathrm{C}_{2} \mathrm{H}_{6}$ mixing ratio is virtually exponential, certainly up to $26 \mathrm{~km}$ altitude and possibly up to $30 \mathrm{~km}$ altitude. A least squares fit gives a scale height of $3.5 \pm 0.15 \mathrm{~km}$ for the decrease. It was calculated excluding the contaminated samples above $30 \mathrm{~km}$ and the two straggling points at 18 and $22 \mathrm{~km}$ altitude from the profile on June 16, 1978. The fitted exponential decrease is also shown in Figure 2 (dash-dotted line).

\section{Discussion}

Very few published data covering the lower stratosphere and upper troposphere are available for comparison. We could not find any other $\mathrm{C}_{3} \mathrm{H}_{8}$ measurements for that altitude range in the literature, and for $\mathrm{C}_{2} \mathrm{H}_{6}$ the only measurements published seem to be those of Cronn and Robinson [1979a, b]. These authors measured the $\mathrm{C}_{2} \mathrm{H}_{6}$ mixing ratio in about 60 samples collected aboard an aircraft over the San Francisco Bay area $\left(37^{\circ} \mathrm{N}\right)$ during April 1977 at altitudes ranging mostly from $2 \mathrm{~km}$ below to $3 \mathrm{~km}$ above the tropopause [Cronn and Robinson, 1979a]. The tropopause altitude ranged between 11.3 and $12 \mathrm{~km}$. Despite a considerable scatter, which the authors ascribed partly to the experimental imprecision, the data showed a clear and steep decrease of the $\mathrm{C}_{2} \mathrm{H}_{6}$ mixing ratio in the lower stratosphere. To avoid confusion, only the range of the $\mathrm{C}_{2} \mathrm{H}_{6}$ values by Cronn and Robinson [1979a] is indicated in Figure 2 by the hatched area. The present data fall well within that range, indicating reasonable agreement in the absolute calibration.

The rapid decrease in the $\mathrm{C}_{2} \mathrm{H}_{6}$ mixing ratio observed by Cronn and Robinson [1979a] in the lower stratosphere is confirmed and extended to higher altitudes by our measurements. It is due to the fast destruction of $\mathrm{C}_{2} \mathrm{H}_{6}$ by $\mathrm{Cl}$ atoms and $\mathrm{OH}$ radicals:

(R1)

$\mathrm{C}_{2} \mathrm{H}_{6}+\mathrm{Cl} \rightarrow \mathrm{C}_{2} \mathrm{H}_{5}+\mathrm{HCl} K_{1}=7.3 \times 10^{-11} \exp (-61 / T)$

(R2)

$\mathrm{C}_{2} \mathrm{H}_{6}+\mathrm{OH} \rightarrow \mathrm{C}_{2} \mathrm{H}_{5}+\mathrm{H}_{2} \mathrm{O} \quad K_{2}=1.86 \times 10^{-11} \exp (-1230 / T)$

[Manning and Kurylo, 1977; Greiner, 1970].

Similarly, $\mathrm{C}_{3} \mathrm{H}_{8}$ is destroyed by the reactions 
(R3)

$\mathrm{C}_{3} \mathrm{H}_{8}+\mathrm{Cl} \rightarrow \mathrm{C}_{3} \mathrm{H}_{7}+\mathrm{HCl} \quad K_{3}=3.2 \times 10^{-} \exp (-340 / T)$

(R4)

$\mathrm{C}_{3} \mathrm{H}_{8}+\mathrm{OH} \rightarrow \mathrm{C}_{3} \mathrm{H}_{7}+\mathrm{H}_{2} \mathrm{O} \quad K_{4}=1.4 \times 10^{-11} \exp (-675 / T)$

[Trotman-Dickenson and Milne, 1967; Greiner, 1970].

At stratospheric temperatures the rate constants for the reaction with $\mathbf{C l}$ are much faster than those for reaction with $\mathrm{OH}$. Thus reaction with $\mathrm{Cl}$ is a significant or even the dominant loss path in both cases, despite the fact that the stratospheric concentrations of $\mathrm{Cl}$ are much lower than those of $\mathrm{OH}$. On the basis of model-calculated vertical profiles of $\mathrm{Cl}$ and $\mathrm{OH}$ concentration (cf. Figure 3), $90 \%$ of the stratospheric destruction of $\mathrm{C}_{2} \mathrm{H}_{6}$ is due to reaction with $\mathrm{Cl}$.

Because of its fast reaction with $\mathrm{Cl}$ atoms the presence of $\mathrm{C}_{2} \mathrm{H}_{6}$ tends to lower the $\mathrm{Cl}$ concentration at those stratospheric altitudes where $\mathrm{C}_{2} \mathrm{H}_{6}$ is still present in significant mixing ratios [Aikin et al., 1979]. This is also demonstrated in Figure 3 by the $\mathrm{Cl}$ profiles predicted from our one-dimensional (1-D) steady state model of stratospheric chemistry: Below 18 $\mathrm{km}$ altitude the $\mathrm{Cl}$ profile influenced by $\mathrm{C}_{2} \mathrm{H}_{6}$ (dash-dotted curve) falls significantly below the $\mathrm{Cl}$ profile, which neglects the presence of $\mathrm{C}_{2} \mathrm{H}_{6}$ (solid curve). The maximum reduction of about a factor of 3 is reached around the tropopause. Owing to the steep decrease of $\mathrm{C}_{2} \mathrm{H}_{6}$ in the model, its influence on the $\mathrm{Cl}$ profile above $18 \mathrm{~km}$ is negligible.

The presence of $\mathrm{C}_{3} \mathrm{H}_{8}$ also reduces the $\mathrm{Cl}$ concentration. The reduction is largest around the tropopause, about $40 \%$, and drops rapidly with increasing altitude. Above $14 \mathrm{~km}$ altitude the effect is negligible. The effect of $\mathrm{C}_{3} \mathrm{H}_{8}$ is not included in the $\mathrm{Cl}$ profiles shown in Figure 3.

The $\mathrm{Cl}$ and $\mathrm{OH}$ profiles in Figure 3 were calculated for spring, $45^{\circ} \mathrm{N}$ latitude, and a tropopause altitude of $11 \mathrm{~km}$, in order to match the average solar flux, temperature, and transport conditions prevailing during the time of sample collection. They are diurnally averaged. The total chlorine mixing ratio $\left(\mathrm{Cl}, \mathrm{ClO}, \mathrm{ClONO}_{2}\right.$, and $\left.\mathrm{HCl}\right)$ in the model is $2.5 \mathrm{ppb}$ at $30 \mathrm{~km}$ altitude. The model utilizes the chemistry and rate constants described by Hudson and Reed [1979]. The details have been described elsewhere [Röth et al., 1980]. Both $\mathrm{Cl}$ and $\mathrm{OH}$ profiles compare favorably with those predicted by other I-D models using similar chemistry [cf. Chameides and Cicerone, 1978; National Academy of Sciences, 1979; J. S. Chang, private communication, 1979].

The model calculations also predicted the $\mathrm{C}_{2} \mathrm{H}_{6}$ and $\mathrm{C}_{3} \mathrm{H}_{8}$ profiles at $45^{\circ} \mathrm{N}$. The above reactions were the only destruction paths included for the higher hydrocarbons; reaction with $O^{1} D$ remains negligible. There are no known production mechanisms for $\mathrm{C}_{2} \mathrm{H}_{6}$ in the stratosphere. The boundary conditions at the ground were based on measured mixing ratios at mid-latitudes: $2 \mathrm{ppb}$ for $\mathrm{C}_{2} \mathrm{H}_{6}$ and $0.4 \mathrm{ppb}$ for $\mathrm{C}_{3} \mathrm{H}_{8}$. The predicted profiles are also included in Figures 1 and 2 (solid curves). In order to demonstrate the importance of the reaction with $\mathrm{Cl}$ atoms, profiles neglecting the $\mathrm{Cl}$ reactions, (R1) and (R3), were also calculated (dashed curves).

The $\mathrm{C}_{3} \mathrm{H}_{8}$ data (Figure 1) are too few at present to warrant detailed investigation; nevertheless, within the observed scatter and experimental error the data and predicted profiles seem to agree.

The $\mathrm{C}_{2} \mathrm{H}_{6}$ data are much more interesting in the sense that they show a significant and systematic deviation over a large altitude range from the rapid decrease predicted by the 1-D steady state model. The deviation is rather large: At $20 \mathrm{~km}$ al-

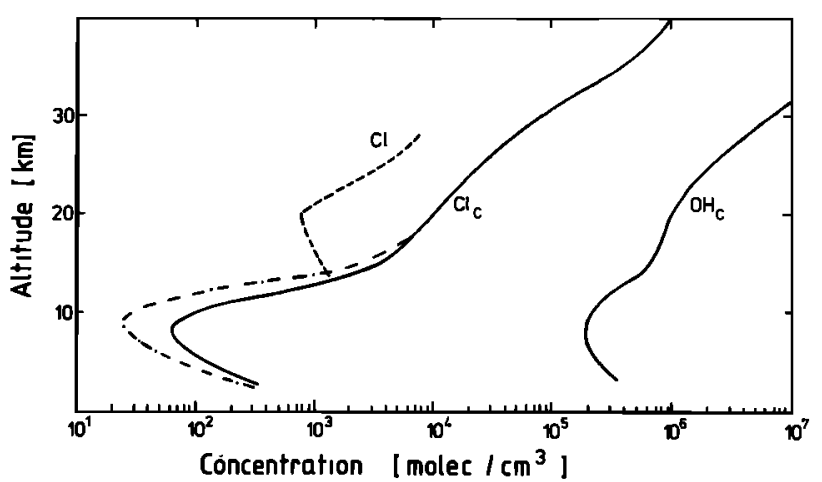

Fig. 3. Vertical profiles of $\mathrm{Cl}$ atom and $\mathrm{OH}$ radical concentrations in the stratosphere. The profiles $\mathrm{Cl}_{c}$ and $\mathrm{OH}_{c}$ were calculated from a one-dimensional steady state model. The calculated $\mathrm{Cl}$ profile changes to the dash-dotted curve when the presence of $\mathrm{C}_{2} \mathrm{H}_{6}$ is taken into account. The upper limit for the $\mathrm{Cl}$ concentration estimated from the measured $\mathrm{C}_{2} \mathrm{H}_{6}$ data is given by the dashed curve.

titude the measured mixing ratio is 1 order of magnitude higher and at $25 \mathrm{~km}$ altitude, 2 orders of magnitude higher than the model-calculated values. Such a comparison could be questioned. The model, whose transport has been reduced to simple vertical eddy diffusion, constructs a temporally and horizontally averaged profile, whereas the experimental profiles are subject not only to temporal variations in the local $\mathrm{C}_{2} \mathrm{H}_{6}$ mixing ratio but also to fluxes, which can have vertical and horizontal, turbulent and advective components. It is likely that the measured $\mathrm{C}_{2} \mathrm{H}_{6}$ data do deviate to some extent from the local average, certainly from the global average as it is defined by a 1-D model. The question is whether a local and temporary transport perturbation can enhance the $\mathrm{C}_{2} \mathrm{H}_{6}$ mixing ratio by as much as is observed here. If not, we have to admit the possibility of a lower stratospheric destruction rate of $\mathrm{C}_{2} \mathrm{H}_{6}$.

To that end, the various models of transport need to be discussed and checked against the available information. We first note that the experimental data consist of two sets which, although sampled about 2 weeks apart, superimpose quite well to form the same general profile. The temporal variations were small at most altitudes. On the other hand the modelcalculated lifetimes of $\mathrm{C}_{2} \mathrm{H}_{6}$ for chemical destruction, $\tau_{c}$, is short. It decreases from 20 days at $20 \mathrm{~km}$ altitude to 2 days at $30 \mathrm{~km}$ altitude (Figure 4). Thus if the profile collected on June 16,1979 , had been due to a momentary perturbation of the modeled average profile, the mixing ratios in the upper part should have relaxed toward that average profile by June 28 , 1979, when the next profile was collected. Such a relaxation was not observed. Either stratospheric destruction of $\mathrm{C}_{2} \mathrm{H}_{6}$ was much slower than was predicted by the model, or it was matched by a large divergence of the $\mathrm{C}_{2} \mathrm{H}_{6}$ flux. In any case the transport pattern which established and maintained the measured $\mathrm{C}_{2} \mathrm{H}_{6}$ profile must have persisted longer than the $\mathrm{C}_{2} \mathrm{H}_{6}$ lifetime at the higher altitudes, at least for a few weeks.

With that, one mode of transport can be dismissed as unlikely. Transport by a mean vertical wind component would require velocities around $2 \mathrm{~cm} / \mathrm{s}$ at $30 \mathrm{~km}$ and $0.5 \mathrm{~cm} / \mathrm{s}$ at 25 $\mathrm{km}$ altitude to maintain the observed $\mathrm{C}_{2} \mathrm{H}_{6}$ profile against a destruction characterized by $\tau_{c}$. Persistence of that mode for several weeks would push the mixing ratios of the longer-lived trace gases $\mathrm{CH}_{4}, \mathrm{~N}_{2} \mathrm{O}, \mathrm{CF}_{2} \mathrm{Cl}_{2}$, and $\mathrm{CFCl}_{3}$ at 25 or $30 \mathrm{~km}$ alti- 


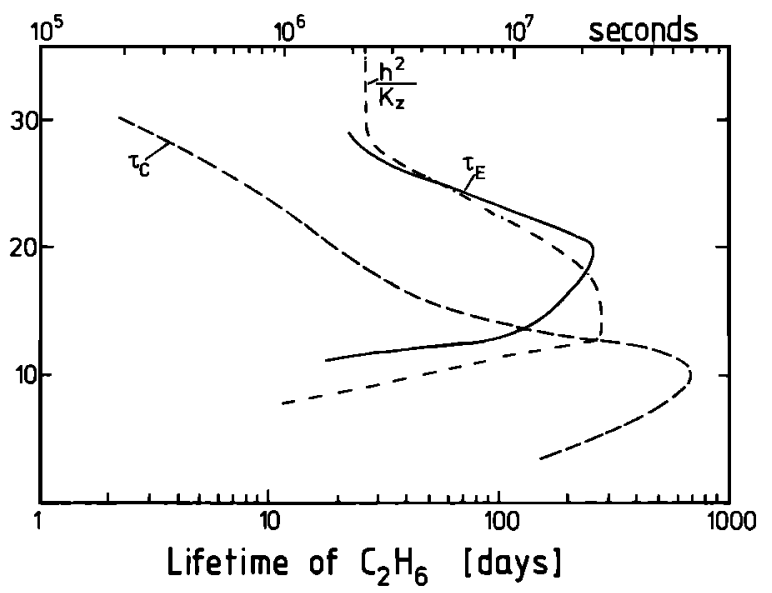

Fig. 4. Vertical profile of the $\mathrm{C}_{2} \mathrm{H}_{6}$ lifetime in the stratosphere: $\tau_{c}$ represents the model prediction, and $\tau_{E}$ is derived from the measured $\mathrm{C}_{2} \mathrm{H}_{6}$ profile. The leading term of $\tau_{E}, h^{2} / K_{z}$ is also shown.

tude to much higher values than were actually observed in the present flights [Fabian et al., 1979b].

Increased vertical eddy diffusion is not so readily dismissed. In this case, which implies vertical mixing, the time with which the profile responds to a change in transport rate depends on the chemical lifetime of the molecule considered. Since $\mathrm{C}_{2} \mathrm{H}_{6}$ is much shorter lived, its profile might have approached a form such as that measured without a noticeable, simultaneous change in the measured $\mathrm{CH}_{4}$ or $\mathrm{N}_{2} \mathrm{O}$ profiles. To maintain the observed $\mathrm{C}_{2} \mathrm{H}_{6}$ profile, values of the vertical eddy diffusion coefficient 4 times higher than those used in our 1-D model are required, that is, $K_{2}=3 \times 10^{4} \mathrm{~cm}^{2} / \mathrm{s}$ at 20 $\mathrm{km}$ and $K_{z}=2 \times 10^{5} \mathrm{~cm}^{2} / \mathrm{s}$ at $30 \mathrm{~km}$ altitude. Such values, however, are rather high for the season and latitude considered [cf. Climatic Impact Assessment Program, 1975; Schmeltekopf et al., 1977] and are not likely to persist for a long time.

Finally, we have to consider horizontal flow. This possibility still requires fast upward transport somewhere, to generate high $\mathrm{C}_{2} \mathrm{H}_{6}$ concentrations at higher altitudes. Furthermore, the sampling flights were launched during a period of weak easterly flow in the stratosphere over the Eurasian continent which persisted during most of June, as evidenced by the constant pressure charts between 50 and 10 mbar. This leaves little chance for large-scale, horizontal transport fast enough to overcome the fast model-calculated destruction and increase the local $\mathrm{C}_{2} \mathrm{H}_{6}$ mixing ratios to the observed values. There is, however, some indication that horizontal transport can cause fluctuations in the observed mixing ratios. Many stratospheric profiles of the longer-lived source gases, for example, $\mathrm{CH}_{4}, \mathrm{~N}_{2} \mathrm{O}$, and $\mathrm{CF}_{2} \mathrm{Cl}_{2}$ measured over southern France, and the present ones are no exception, show mixing ratios slightly (about $10 \%$ ) but systematically increased over the latitudinal average at $25-30 \mathrm{~km}$ altitudes. Though less pronounced, the feature is very similar to that observed over $30^{\circ} \mathrm{N}$ latitude and has been ascribed to meridional transport [Ehhalt and Tönnissen, 1979]. On the average, however, this mode of transport seems slow, since $\mathrm{H}_{2}$ which is produced during the destruction of $\mathrm{CH}_{4}$ on a time scale of years is also slightly increased. Because it is a relatively slow process and because the fluctuations induced by it on the longer-lived trace gases are small, meridional transport is not likely to cause the large discrepancy observed in the $\mathrm{C}_{2} \mathrm{H}_{6}$ profile.

There is also a more general argument which places a limit on any transport-caused deviation from the average $\mathrm{C}_{2} \mathrm{H}_{6}$ profile. $\mathrm{CFCl}_{3}$ and $\mathrm{CF}_{2} \mathrm{Cl}_{2}$ reach vertical gradients and chemical lifetimes in the middle stratosphere similar to the ones of $\mathrm{C}_{2} \mathrm{H}_{6}$ in the lower stratosphere. In fact, at mid-latitudes the measured gradient of $\mathrm{CFCl}_{3}$ approaches the model-calculated one of $\mathrm{C}_{2} \mathrm{H}_{6}$ already at $20 \mathrm{~km}$ altitude. The lifetime of $\mathrm{CFCl}_{3}$ is 1 month at $30 \mathrm{~km}$ altitude. Therefore by analogy, $\mathrm{C}_{2} \mathrm{H}_{6}$ profiles in the lower stratosphere should respond to similar changes in the transport with similar deviations from the average, as do $\mathrm{CFCl}_{3}$ and $\mathrm{CF}_{2} \mathrm{Cl}_{2}$ in the middle stratosphere. The scatter of the $\mathrm{CFCl}_{3}$ data should provide an estimate for the expected deviations from the average $\mathrm{C}_{2} \mathrm{H}_{6}$ profile. The observed $\mathrm{CFCl}_{3}$ and $\mathrm{CF}_{2} \mathrm{Cl}_{2}$ mixing ratios around and above 30 $\mathrm{km}$ altitude deviate not more than a factor of 5 from the measured average [Fabian et al., 1979b]. This should represent a reasonable upper limit on the transport-caused deviation from the average $\mathrm{C}_{2} \mathbf{H}_{6}$ profile. The limit is conservative because it includes the error of the $\mathrm{CFCl}_{3}$ measurement, which becomes quite large for the small concentrations above $30 \mathrm{~km}$ altitude. The upper limit of a factor of 5 is much less than the deviation between measured and model-calculated $\mathrm{C}_{2} \mathrm{H}_{6}$ profiles, which has increased to a factor of 100 at $25 \mathrm{~km}$ altitude (cf. Figure 2).

None of the arguments given above is sufficiently strong to exclude transport as being at least partly responsible for the deviation between measured and calculated $\mathrm{C}_{2} \mathrm{H}_{6}$ profiles. In fact, such deviations are to be expected. However, because the difference between the measured $\mathrm{C}_{2} \mathrm{H}_{6}$ profile and the one predicted by the 1-D steady state model is so large, it is diffcult to blame it all on a peculiar transport pattern. More likely, the model-calculated destruction rate of $\mathrm{C}_{2} \mathrm{H}_{6}$ is overestimated. Because reaction with $\mathrm{OH}$ contributes only $10 \%$ of the total destruction above $20 \mathrm{~km}$ altitude, that reaction path can be excluded. Apparently, the measured $\mathrm{C}_{2} \mathrm{H}_{6}$ profile demands a lower $\mathrm{Cl}$ concentration than that predicted by our or other present 1-D models, since the reaction rate constant $K_{1}$, by Manning and Kurylo [1977], used here appears to be essentially correct. Except for an old measurement by Fettis and Knox [1964] which gave a rate constant nearly a factor of 2 slower, the published data of Davis et al. [1970] and Baulch et al. [1980], who cited unpublished data of R. J. Lewis et al. (1980), R. T. Watson et al. (1980), and R. T. Watson and G. Ray (1980), agree with the measurements of Manning and $\mathrm{Ku}$ rylo [1977] to better than $20 \%$ for the whole stratospheric temperature range. To explain the observed $\mathrm{C}_{2} \mathrm{H}_{6}$ profile, the rate constant $K_{1}$ would have to be slower by a factor of 4 .

Because the measured $\mathrm{C}_{2} \mathrm{H}_{6}$ profile in Figure 2 may differ considerably from the global average, a definite profile of the $\mathrm{Cl}$ atom concentration cannot be derived. To estimate how much the $\mathrm{Cl}$ concentration in the lower stratosphere may differ from the model-predicted one, we proceed with the assumptions that the measured $\mathrm{C}_{2} \mathrm{H}_{6}$ profile represents the global average and that transport can be described by vertical eddy diffusion as in the 1-D model. With that we can estimate the vertical flux divergence of $\mathrm{C}_{2} \mathrm{H}_{6}$, which in steady state is balanced by the destruction rate of $\mathrm{C}_{2} \mathrm{H}_{6}$. It is expressed as the inverse of the destruction time, or chemical lifetime, $\tau_{E}$ :

$$
\tau_{E}^{-1}=\frac{1}{\rho M} \cdot \frac{\partial}{\partial z}\left[\rho \cdot K_{z} \cdot \frac{\partial M}{\partial z}\right]=K_{1}[\mathrm{Cl}]+K_{2}[\mathrm{OH}]
$$

where $M$ is the measured $\mathrm{C}_{2} \mathrm{H}_{6}$ mixing ratio, $\rho$ the number density of air, and $K_{z}$ the eddy diffusion coefficient used in our 
model. The resulting (experimental) $\tau_{E}$ is shown in Figure 4. Since the measured mixing ratio profile fits an exponential decrease with a scale height $h=3.5 \pm 0.15 \mathrm{~km}$ (see above), the height dependence of $\tau_{E}$ is dominated by that of $\rho$ and $K_{z} ; \tau_{E}$ is often approximated by $h^{2} / K_{z}$, which is also shown in Figure 4. From it the form of our $K_{z}$ profile can be easily derived. For comparison the model-predicted lifetime of $\mathrm{C}_{2} \mathrm{H}_{6}$ is also shown in Figure 4. It is given by

$$
\tau_{c}^{-1}=K_{1}[\mathrm{Cl}]_{c}+K_{2}[\mathrm{OH}]_{c}=\frac{1}{\rho M_{c}} \cdot \frac{\partial}{\partial z}\left[\rho \cdot K_{z} \cdot \frac{\partial M_{c}}{\partial z}\right]
$$

where the quantities to the right are all taken from the model.

The comparison given by Figure 4 shows clearly that $\tau_{E}$ is substantially longer than $\tau_{c}$ above $14 \mathrm{~km}$ altitude. In the lower stratosphere the experimental lifetimes of $\mathrm{C}_{2} \mathrm{H}_{6}, \tau_{E}$, range between 200 and 20 days, which would also tend to decrease the transport-caused deviations from the average $\mathrm{C}_{2} \mathrm{H}_{6}$ profile. Obviously, the experimentally deduced destruction rate of $\mathrm{C}_{2} \mathrm{H}_{6}$ by $\mathrm{Cl}$ is smaller than that predicted by the model. In order to obtain an estimate for the $\mathrm{Cl}$ profile that would explain our $\mathrm{C}_{2} \mathrm{H}_{6}$ measurements, we use equation (1); $\tau_{E}$ is taken from Figure 4, and $K_{1}$ from Manning and Kurylo [1977]. Reaction with $\mathrm{OH}$ is neglected. Consequently, the $\mathrm{Cl}$ concentrations are overestimated, and the derived $\mathrm{Cl}$ profile presents rather an upper limit. It is shown in Figure 3 as profile $\mathrm{Cl}$. The $\mathrm{Cl}$ concentrations derived from the measured $\mathrm{C}_{2} \mathrm{H}_{6}$ are considerably lower (up to a factor of 10 ) than the model-predicted profile. Below $20 \mathrm{~km}$ altitude an increasing fraction of $\mathrm{C}_{2} \mathrm{H}_{6}$ reacts with $\mathrm{OH}$. There the neglect of reaction with $\mathrm{OH}$ leads to a considerable overestimate of the $\mathrm{Cl}$ concentration, which causes the derived upper limit to curve to higher $\mathrm{Cl}$ concentrations. Introduction of the new reaction rate for $\mathrm{OH}$ and $\mathrm{HNO}_{3}$ [Wine et al., 1981] would decrease the model-calculated $\mathrm{Cl}$ profile in the lower stratosphere by a factor of 1.5-2 (S. Liu, private communication, 1980). Even so, the derived upper limit remains considerably lower than the model-calculated $\mathrm{Cl}$ profile. Clearly, if subsequent measurements give a global $\mathrm{C}_{2} \mathrm{H}_{6}$ profile similar to the present measurements, a substantial revision of the $\mathrm{Cl}$ concentration in the lower stratosphere will be required. The above $\mathrm{Cl}$ concentrations are averages over the lifetime of $\mathrm{C}_{2} \mathrm{H}_{6}$. Because transport within the estimated lifetimes of $\mathrm{C}_{2} \mathrm{H}_{6}$ (20-200 days) can be extensive, the $\mathrm{Cl}$ values should also represent a large-scale horizontal average.

Given the preliminary and limited nature of the $\mathrm{C}_{2} \mathrm{H}_{6}$ data, much of the foregoing discussion is somewhat tentative. Nevertheless, the present analysis shows for our assumptions and for one particular case that the average $\mathrm{Cl}$ concentration in the lower stratosphere is lower than that predicted by current models. It is interesting to note that the $\mathrm{ClO}$ measurements by Anderson et al. [1977] in the lower stratosphere also give values lower by up to a factor of 5 than the 1-D model calculations. The analysis also shows that extensive stratospheric $\mathrm{C}_{2} \mathrm{H}_{6}$ measurements of sufficient accuracy are a useful tool for determining the average $\mathrm{Cl}$ concentration in the lower stratosphere.

\section{ConCLUSION}

It has been shown that the measurement of $\mathrm{C}_{2} \mathrm{H}_{6}$ can be used to derive profiles of atomic chlorine in the lower stratosphere. This is especially interesting, because the only available technique for measuring $\mathrm{Cl}$ directly, resonance fluores- cence, is restricted to higher altitudes. Even though $\mathrm{ClO}$ can be measured to as low as $25 \mathrm{~km}$ altitude, the resonance fluorescence technique does not provide measurements of atomic $\mathrm{Cl}$ below $35 \mathrm{~km}$ altitude [Anderson et al., 1977]. For this reason there is also no altitude overlap with our estimate of $\mathbf{C l}$ from $\mathrm{C}_{2} \mathrm{H}_{6}$ measurements, and thus a direct comparison with the $\mathrm{Cl}$ data by Anderson et al. [1977] is not feasible. Because a considerable fraction, about one half, of the $\mathrm{O}_{3}$ destruction by $\mathrm{ClO}_{x}$ proceeds below $30 \mathrm{~km}$, the implication of lower $\mathrm{Cl}$ concentrations at these lower altitudes is important in the estimate of anthropogenic perturbations, and a measurement of the $\mathrm{Cl}$ at these lower altitudes is of great interest. If the problem of contamination can be overcome, which seems feasible, the measurement of $\mathrm{C}_{2} \mathrm{H}_{6}$ by our technique could probably be extended to $35 \mathrm{~km}$ and provide data for calculation of an average vertical $\mathrm{Cl}$ profile in the lower and middle stratosphere.

Acknowledgments. We would like to thank P. Fabian of the MaxPlanck-Institut fur Aeronomie in Lindau, who made available the stratospheric samples. Likewise, we thank W. Seiler of the MaxPlanck-Institut für Chemie in Mainz, who provided the tropospheric samples. This paper is dedicated to $K$. H. Lieser in honor of his sixtieth birthday.

\section{REFERENCES}

Aiken, A. C., J. R. Herman, and E. J. Maier, Ethane and ethylene behaviour in the atmosphere, Proceedings of the NATO Advanced Study Institute on Atmospheric Ozone, Aldeia das Acoteias, Portugal, Rep. FAA-EE-80-20, pp. 191-208, Fed. Aviat. Admin., Washington, D. C., 1979.

Anderson, G. J., J. J. Margitan, and J. H. Stedman, Atomic chlorine and chlorine monoxide radical in the stratosphere: Three in situ observations, Science, 198, 501-503, 1977.

Baulch, D. L., R. A. Cox, R. F. Hampson, Jr., J. A. Korr, J. Troe, and R. T. Watson, Evaluated kinetic and photochemical data for atmospheric chemistry, J. Phys. Chem. Ref. Data, 9, 425, 1980.

Chameides, W. L., and R. J. Cicerone, Effects of nonmethane hydrocarbons in the atmosphere, J. Geophys. Res., 83, 947-950, 1978.

Climatic Impact Assessment Program, CIAP Monograph I: The Natural Stratosphere of 1974, Rep. DOT-TST-75-51, Dep. of Transp., Washington, D. C., 1975.

Cronn, D., and E. Robinson, Tropospheric and lower stratospheric vertical profiles of ethane and acetylene, Geophys. Res. Lett., 6, 641-644, 1979a.

Cronn, D. R., and E. Robinson, Determination of trace gases in Learjet and U-2 whole air samples during the Intertropical Convergence Zone Experiment, 1977 Intertropical Convergence Zone Experiment, NASA Tech. Memo, TM 78577, 61-65, $1979 b$.

Davis, D. D., W. Braun, and A. M. Bass, Reactions of $\mathrm{Cl}^{2} \mathrm{P}_{3 / 2}$ : Absolute rate constants for reaction with: $\mathrm{H}_{2}, \mathrm{CH}_{4}, \mathrm{C}_{2} \mathrm{H}_{6}, \mathrm{CH}_{2} \mathrm{Cl}_{4}, \mathrm{C}_{2} \mathrm{Cl}_{4}$ and $c-\mathrm{C}_{6} \mathrm{H}_{12}$, Int. J. Chem. Kinet., 2, 101, 1970.

Ehhalt, D. H., and A. Tönnissen, Hydrogen and carbon compounds in the stratosphere, Proceedings of the NATO Advanced Study Institute on Atmospheric Ozone, Aldeia das Acoteias, Portugal, Rep. $F A A-E E-80-20$, pp. 129-152, Fed. Aviat. Admin., Washington, D. C., 1979.

Fabian, P., R. Borchers, K. H. Weiler, U. Schmidt, A. Volz, D. H. Ehhalt, W. Seiler, and F. Müller, Simultaneously measured vertical profiles of $\mathrm{H}_{2}, \mathrm{CH}_{4}, \mathrm{CO}, \mathrm{N}_{2} \mathrm{O}, \mathrm{CFCl}_{3}$, and $\mathrm{CF}_{2} \mathrm{Cl}_{2}$ in the mid-latitude stratosphere and troposphere, J. Geophys. Res., 84, 3149-3154, $1979 a$.

Fabian, P., R. Borchers, K. H. Weiler, U. Schmidt, A. Volz, D. H. Ehhalt, W. Seiler, and F. Muller, The vertical distribution of $\mathbf{H}_{2}, \mathrm{CH}_{4}$, $\mathrm{N}_{2} \mathrm{O}, \mathrm{CFCl}_{3}$ and $\mathrm{CF}_{2} \mathrm{Cl}_{2}$ at midlatitudes, paper presented at 17 th General Assembly, IUGG, Canberra, Australia, Dec. 2-15, $1979 b$.

Fettis, G. C., and J. H. Knox, The rate constants of halogen atom reactions, Prog. React. Kinet., 2, 1-38, 1964.

Greiner, N. R., Hydroxyl radical kinetics by kinetic spectroscopy, V. Reactions with alkanes in the range 300-500 K, J. Chem. Phys., 53, 1070-1076, 1970.

Hudson, R. D., and E. J. Reed (Eds.), The stratosphere: Present and future, NASA Ref. Publ., 1049, 1979. 
Lueb, R. A., D. H. Ehhalt, and L. E. Heidt, Balloon borne low temperature air sampler, Rev. Sci. Instrum., 46, 702-705, 1975.

Manning, R., and M. J. Kurylo, Flash photolysis resonance investigation of the temperature dependencies of the reaction of $\mathrm{Cl}\left({ }^{2} \mathrm{P}\right)$ atoms with $\mathrm{CH}_{4}, \mathrm{CH}_{3} \mathrm{Cl}, \mathrm{CH}_{3} \mathrm{~F}, \mathrm{CH}_{3} \mathrm{~F}^{\star}$, and $\mathrm{C}_{2} \mathrm{H}_{6}, J$. Phys. Chem., 81, 291-296, 1977.

National Academy of Sciences, Stratospheric ozone, depletion by halocarbons: Chemistry and transport, report, Panel on Stratospheric Chem. and Transp., Washington, D. C., 1979.

Rőth, E. P., A. Tönnissen, and T. Janssen-Schmidt, Report from Study Group III (Modelling) on the ozone depletion problem, edited by I. G. Brasseur, Comm. of the Eur. Communities, Brussels, in press, 1980.

Rudolph, J., D. H. Ehhalt, and G. Gravenhorst, Recent measurements of light hydrocarbons in remote areas, in Proceedings of the First European Symposium on Physico-Chemical Behaviour of Atmospheric Pollutants, Ispra, pp. 41-51, Comm. of the Eur. Communities, Brussels, 1979.
Schmeltekopf, A. L., D. L. Albritton, P. J. Crutzen, P. D. Goldan, W. J. Harrop, W. R. Henderson, J. R. McAfee, M. McFarland, H. I. Schiff, T. L. Thompson, D. J. Hofman, and N. T. Kjome, Stratospheric nitrous oxide altitude profiles at various latitudes, $J$. Atmos. Sci., 34, 729-736, 1977.

Trotman-Dickenson, A. F., and G. S. Milne, Tables of bimolecular gas reactions, Rep. NSRDS-NBS 9, Natl. Bur. Stand., Washington, D. C., 1967.

Wine, P. H., A. R. Ravishankara, N. M. Kreutter, R. C. Shah, J. M. Nicovich, R. L. Thompson, and D. J. Wuebbles, Rate of reaction of $\mathrm{OH}$ with $\mathrm{HNO}_{3}, J$. Geophys. Res., 86, 1105-1112, 1981.

(Received October 13, 1980; revised March 10, 1981; accepted March 12, 1981.) 